\title{
Reassessment of Solid Solubilities and Thermodynamic Properties of Magnesium and Calcium in Silicon
}

\author{
Sakiko Kawanishi ${ }^{1}$ and Takeshi Yoshikawa ${ }^{2}$ \\ ${ }^{1}$ Institute of Multidisciplinary Research for Advanced Materials, Tohoku University, Sendai 980-8577, Japan \\ ${ }^{2}$ Institute of Industrial Science, The University of Tokyo, Tokyo 153-8505, Japan
}

To obtain fundamental knowledge on the behavior of magnesium $(\mathrm{Mg}$ ) and calcium $(\mathrm{Ca})$ in solid silicon ( $\mathrm{Si}$ ) during solidification, the solid solubilities of $\mathrm{Mg}$ and $\mathrm{Ca}$ in $\mathrm{Si}$ were reinvestigated by temperature-gradient zone melting method. Solubilities were measured to be $0.0016-0.0041 \mathrm{~mol} \%$ for $\mathrm{Mg}$ and $0.0006-0.0021 \mathrm{~mol} \%$ for $\mathrm{Ca}$ at $1373-1623 \mathrm{~K}$. The excess Gibbs energies of $\mathrm{Mg}$ and Ca in solid Si were determined from their solid solubilities as follows:

$$
\begin{aligned}
& R T \ln \gamma_{\mathrm{Mg}(s) \text { in solid Si }}^{\circ}=193,000( \pm 52,000)-69.8( \pm 34) \mathrm{T}(\mathrm{J} / \mathrm{mol}) \\
& R T \ln \gamma_{\mathrm{Ca}(s) \text { in solid Si}}^{\circ}=140,000( \pm 35,000)-72.6( \pm 23) \mathrm{T}(\mathrm{J} / \mathrm{mol})
\end{aligned}
$$

[doi:10.2320/matertrans.M2016323]

(Received September 14, 2016; Accepted December 5, 2016; Published January 20, 2017)

Keywords: $\quad$ silicon, magnesium, calcium, solid solubility, temperature-gradient zone melting

\section{Introduction}

High-purity silicon ( $\mathrm{Si}$ ) is in demand for the production of semiconductor $\mathrm{Si}$, solar-grade $\mathrm{Si}$ and other chemical applications. Slag treatment is an efficient metallurgical refining process as it enables large-scale and reduced-time operation. During metallurgical grade $\mathrm{Si}$ production, oxidizing treatment is used to remove gangue components as slags from $\mathrm{Si}$ melts that are obtained by quartz reduction in the arc furnace. Slag treatment using calcium-oxide-based slags has been researched to remove boron and phosphorus from $\mathrm{Si}$, and is aimed at solar-grade $\mathrm{Si}$ production ${ }^{1-4)}$. Because magnesium oxide and calcium oxide are major components of slag in both cases, the incorporation of magnesium $(\mathrm{Mg})$ and calcium $(\mathrm{Ca})$ into molten $\mathrm{Si}$ is thermodynamically inevitable $\mathrm{e}^{2,3,5,6)}$ and their behavior during solidification must be understood. Most metal elements have small segregation coefficients in $\mathrm{Si}$, which allows their separation during solidification ${ }^{7)}$. However, the segregation coefficients of $\mathrm{Mg}$ and $\mathrm{Ca}$ in $\mathrm{Si}$ have not been reported and so it is difficult to predict their behavior during Si solidification.

In addition to the segregation coefficients, the solid solubilities of $\mathrm{Mg}$ and $\mathrm{Ca}$ in $\mathrm{Si}$ are important to consider their incorporation into $\mathrm{Si}$, and were only reported by Sigmund ${ }^{8)}$. The author applied temperature-gradient zone melting ${ }^{9)}$ to achieve equilibrium solidification of solid $\mathrm{Si}$ from liquid $\mathrm{Ca}-\mathrm{Si}$ or $\mathrm{Mg}-\mathrm{Si}$ alloys, and measured solubilities as high as $0.012 \mathrm{~mol} \%$ at $1453 \mathrm{~K}$ for $\mathrm{Ca}$ and $0.025 \mathrm{~mol} \%$ at $1473 \mathrm{~K}$ for $\mathrm{Mg}$. However, such high contents of $\mathrm{Ca}$ or $\mathrm{Mg}$ were not found in Si grains after solidification.

In this work, the solid solubilities of $\mathrm{Mg}$ and $\mathrm{Ca}$ in $\mathrm{Si}$ were investigated again using temperature-gradient zone melting experiments at 1323-1623 K. Based on the measured solubilities, thermodynamic properties of $\mathrm{Mg}$ and $\mathrm{Ca}$ in solid $\mathrm{Si}$ were also determined.

\section{Experimental}

Figure 1 shows apparatus that is composed mainly of an induction furnace $(280 \mathrm{kHz})$ that is equipped with a quartz reaction tube (60 $\mathrm{mm}$ OD, $54 \mathrm{~mm}$ ID, $400 \mathrm{~mm}$ length). A Ca (99\% purity) or $\mathrm{Mg}(99 \%)$ film was inserted between two (111)-oriented Si wafers $(10 \times 5 \times 0.6 \mathrm{~mm}, 10 \Omega \cdot \mathrm{cm})$, and the sample set was placed on a graphite susceptor in the reaction tube. After evacuation below $0.5 \mathrm{~Pa}$ with a rotary vacuum pump, the reaction tube was filled with hydrogen. The sample temperature was increased to $1323-1623 \mathrm{~K}$ for $1200-3600 \mathrm{~s}$ by inductively heating the susceptor. The temperature of the bottom surface was controlled by monitoring with a singlecolor pyrometer.

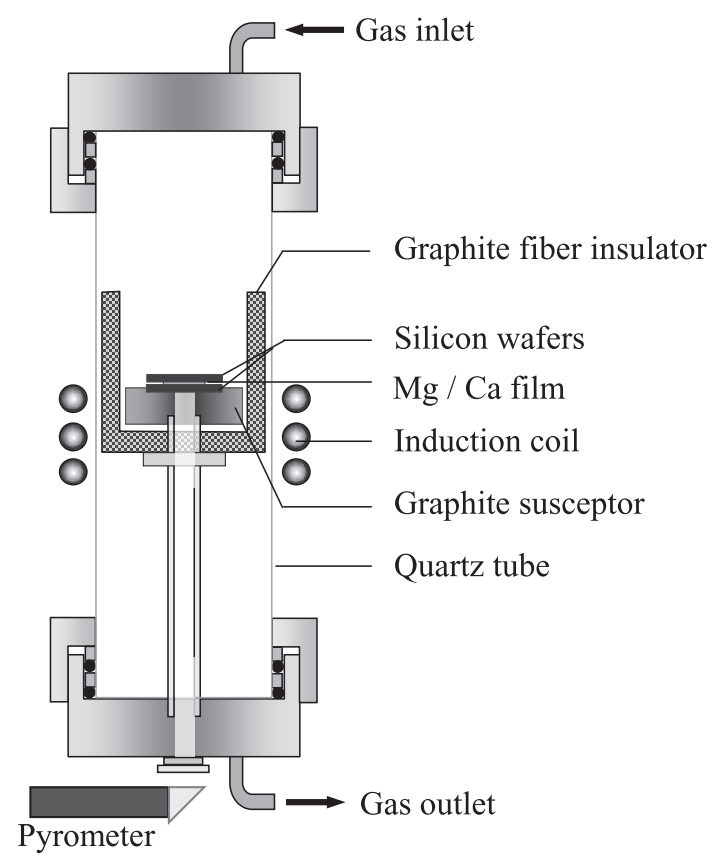

Fig. 1 Schematic image of temperature-gradient zone melting experiment. 
As the sample was heated from the base by the susceptor, the temperature increased in a downward direction. After $\mathrm{Ca}$ or $\mathrm{Mg}$ forms a liquid zone by dissolving the contacted $\mathrm{Si}$, the zone migrates downward in the lower Si wafer along the temperature gradient, which results in the crystallization of an equilibrium solid. When heat that is released at the top surface of the sample is assumed to be controlled by radiation, the temperature gradient in the solid $\mathrm{Si}$ is estimated to be $4.9 \times 10^{3} \mathrm{~K} / \mathrm{m}$ at $1323 \mathrm{~K}$ and $1.1 \times 10^{4} \mathrm{~K} / \mathrm{m}$ at $1623 \mathrm{~K}$ from the emissivity ${ }^{10)}$ and the heat conductivity ${ }^{11)}$ of $\mathrm{Si}$, respectively. The temperature difference in the crystallized $\mathrm{Si}$ is less than $6.6 \mathrm{~K}$ from the thickness of the $\mathrm{Si}$ wafer, and that in the liquid zone is assumed to be less than $2 \mathrm{~K}$ from its thickness $(<0.2 \mathrm{~mm})$.

After the experiments, samples were subjected to electron probe micro analysis (EPMA) with an accelerating voltage of $15 \mathrm{kV}$, a sample current of 100-200 nA and a counting time of $100 \mathrm{~s}$. The intensity of $\mathrm{Ca} \mathrm{K}_{\alpha}$ or $\mathrm{Mg} \mathrm{K}_{\alpha}$ radiation of the crystallized $\mathrm{Si}$ was determined by subtracting the background intensity obtained from the pure single crystalline $\mathrm{Si}$. Thereafter, the $\mathrm{Ca}$ or $\mathrm{Mg}$ content was determined by applying a ZAF correction.

\section{Results and Discussion}

Figure 2 shows a sample cross-section after heat treatment with $\mathrm{Ca}$ addition by heating at $1323 \mathrm{~K}$ for $3600 \mathrm{~s}$. Migration of a liquid $\mathrm{Si}-\mathrm{Ca}$ zone from the original position "A" to position "B" was observed, which suggests a migration velocity of $\sim 4.6 \times 10^{-8} \mathrm{~m} / \mathrm{s}$. Measurements of $\mathrm{Mg}$ and $\mathrm{Ca}$ contents by EPMA were performed at more than 3 positions between $\mathrm{A}$ and B for each sample.

Measured solid solubilities of $\mathrm{Ca}$ and $\mathrm{Mg}$ in $\mathrm{Si}$ are shown in Figs. 3 and 4 along with reported data ${ }^{8)}$ for comparison. Solubilities ranged $0.0016-0.0041 \mathrm{~mol} \%$ for $\mathrm{Mg}$ and $0.0006-$ $0.0021 \mathrm{~mol} \%$ for $\mathrm{Ca}$ at $1373-1623 \mathrm{~K}$, and were below the detection limit at $1323 \mathrm{~K}$. These data are smaller than the reported data. Sigmund determined the solubility in crystallized Si by wet analysis and found an inhomogeneous solubility. As shown in Fig. 2, inclusions were incorporated into crystallized Si in this work. Therefore, an analysis of the content in a certain specimen volume may overestimate the solubility.

The excess partial molar Gibbs energy of $\mathrm{M}(\mathrm{M}=\mathrm{Mg}$ or $\mathrm{Ca}$ ) in solid $\mathrm{Si}$ was evaluated from the measured solid solubility. At equilibrium, the chemical potential of $\mathrm{M}$ in the solid Si is equal to that in the liquid $\mathrm{Si}-\mathrm{M}$ alloy, which can be ex-

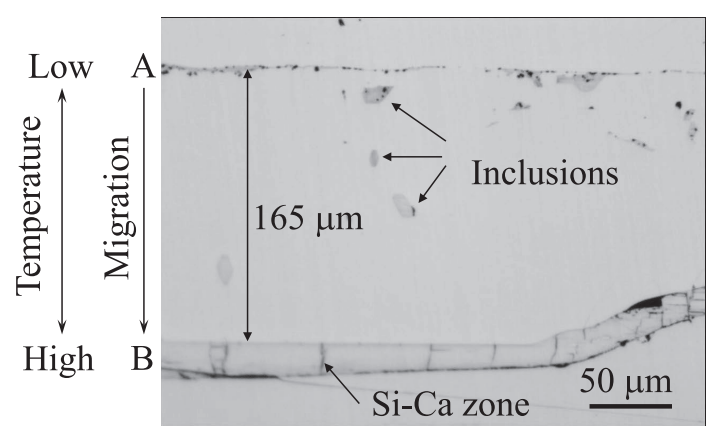

Fig. 2 Cross-section of the sample (Ca, 1323 K, 3600 s). pressed by eqs. (1) and (2):

$$
G_{\mathrm{M}(s)}^{\circ}+R T \ln a_{\mathrm{M}(s) \text { in solid } \mathrm{Si}}=G_{\mathrm{M}(l)}^{\circ}+R T \ln a_{\mathrm{M}(l) \text { in the melt }}
$$

$$
\begin{aligned}
R T & \ln \gamma_{\mathrm{M}(s)} \text { in solid Si } \\
& =\Delta G_{\mathrm{M}}^{\text {fus. }}+R T \ln a_{\mathrm{M}(l) \text { in the melt }}-R T \ln X_{\mathrm{M} \text { in solid Si }}
\end{aligned}
$$

Here, $R T \ln \gamma_{\mathrm{M}(s)}$ in solid $\mathrm{Si}$ is the excess partial molar Gibbs en-

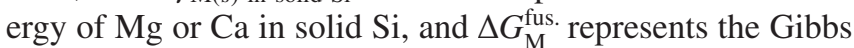
energy of fusion of $\mathrm{Mg}$ or $\mathrm{Ca}^{12)}$. The $\mathrm{Mg}$ or $\mathrm{Ca}$ activity in the liquid phase along the liquidus $\left(a_{\mathrm{M}(l)}\right.$ in the melt $)$ was taken from the reported excess Gibbs energy for the liquid $\mathrm{Si}-\mathrm{Mg}$ or $\mathrm{Si}-$ Ca melt ${ }^{13,14)}$. $X_{\mathrm{M} \text { in solid Si }}$ is the solid solubility as measured in this study. The temperature dependence of $R T \ln \gamma_{\mathrm{M}(s)}^{\circ}$ in solid Si is shown in Fig. 5. Using least-squares regression, the excess partial molar Gibbs energies of $\mathrm{Mg}$ and $\mathrm{Ca}$ in the solid $\mathrm{Si}$ at infinite dilution were determined as shown in eqs. (3) and (4):

$$
\begin{aligned}
& R T \ln \gamma_{\mathrm{Mg}(s) \text { in solid Si }}^{\circ} \\
& \quad=193,000( \pm 52,000)-69.8( \pm 34) T(\mathrm{~J} / \mathrm{mol}) \\
& R T \ln \gamma_{\mathrm{Ca}(s) \text { in solid } \mathrm{Si}}^{\circ} \\
& \quad=140,000( \pm 35,000)-72.6( \pm 23) T(\mathrm{~J} / \mathrm{mol})
\end{aligned}
$$

Here, hexagonal close-packed $\mathrm{Mg}$ and face-centered cubic

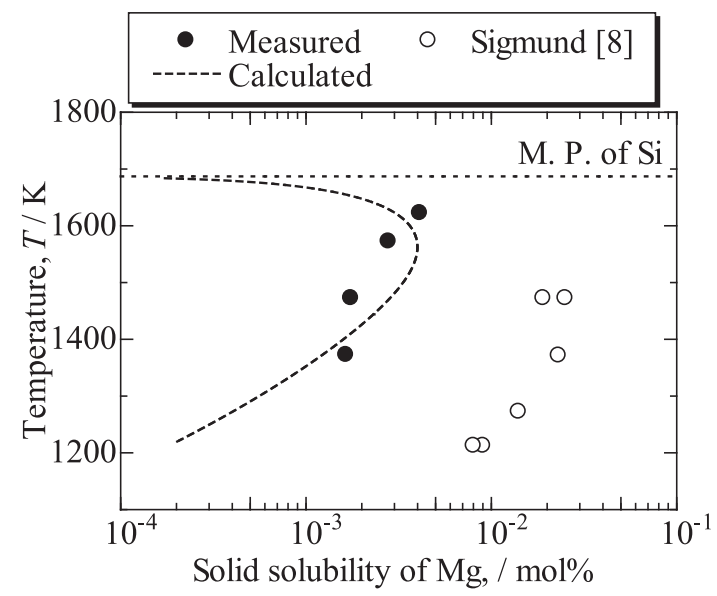

Fig. 3 Solid solubilities of $\mathrm{Mg}$ in $\mathrm{Si}$.

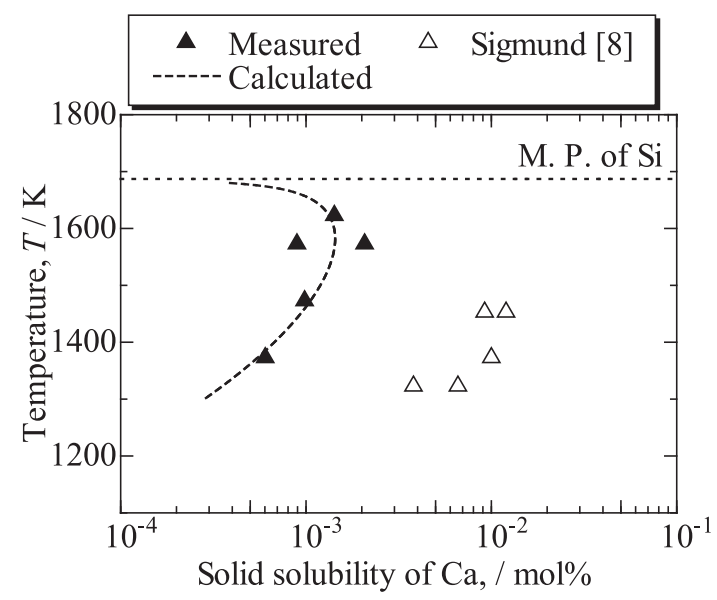

Fig. 4 Solid solubilities of $\mathrm{Ca}$ in Si. 


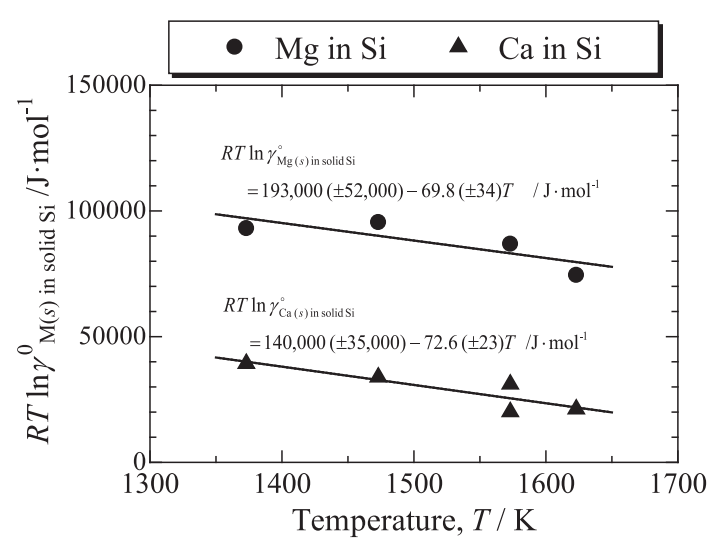

Fig. 5 Excess partial molar Gibbs energy of $\mathrm{Mg}$ and $\mathrm{Ca}$ in solid $\mathrm{Si}$.

Ca were selected as standard states, respectively.

The temperature dependence of the solid solubilities of $\mathrm{Mg}$ and $\mathrm{Ca}$ were derived by inserting eqs. (3) and (4) into eq. (2) as shown by the broken curves of Figs. 3 and 4 . A retrograde solubility was determined for $\mathrm{Mg}$ and $\mathrm{Ca}$, and the maximum solubilities were $0.0040 \mathrm{~mol} \%$ at $1560 \mathrm{~K}$ for $\mathrm{Mg}$ and $0.0014 \mathrm{~mol} \%$ at $1580 \mathrm{~K}$ for Ca.

The segregation coefficient, $\mathrm{k}$, was estimated. When the solid and liquid $\mathrm{Si}$ are equilibrated for small contents of $\mathrm{Mg}$ or $\mathrm{Ca}$, eq. (2) can be rearranged as:

$$
\begin{aligned}
R T \ln \gamma_{\mathrm{M}(s) \text { in solid } \mathrm{Si}}^{\circ} & \Delta G_{\mathrm{M}}^{\mathrm{fus.}}+R T \ln \gamma_{\mathrm{M}(l) \text { in liquid } \mathrm{Si}}^{\circ} \\
& +R T \ln X_{\mathrm{M} \text { in liquid } \mathrm{Si}} \\
& -R T \ln X_{\mathrm{M} \text { in solid } \mathrm{Si}}
\end{aligned}
$$

$$
\begin{aligned}
R T \ln k & =R T \ln \frac{X_{\mathrm{M} \text { in solid } \mathrm{Si}}}{X_{\mathrm{M} \text { in liquid } \mathrm{Si}}} \\
& =\Delta G_{\mathrm{M}}^{\mathrm{fus} .}+R T \ln \gamma_{\mathrm{M}(l) \text { in liquid } \mathrm{Si}}^{\circ}-R T \ln \gamma_{\mathrm{M}(s) \text { in solid } \mathrm{Si}}^{\circ}
\end{aligned}
$$

Extrapolating eqs. (3) and (4) to the melting temperature and using the excess partial Gibbs energy in the liquid Si at in-

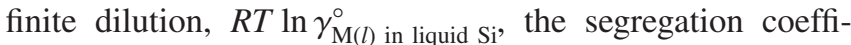
cient, can be obtained from the Gibbs energy of the liquid $\mathrm{Si}-\mathrm{Mg}$ or $\mathrm{Si}-\mathrm{Ca}$ alloy and was found to be 0.00021 for $\mathrm{Mg}$ and 0.00029 for $\mathrm{Ca}$. As is known for other metal elements ${ }^{15}$, $\mathrm{Mg}$ and $\mathrm{Ca}$ show strong segregation tendencies in $\mathrm{Si}$.

\section{Conclusions}

To determine the solid solubilities of $\mathrm{Mg}$ and $\mathrm{Ca}$ in solid $\mathrm{Si}$, temperature-gradient zone melting experiments were performed at $1323-1623 \mathrm{~K}$. The following results were obtained:

(1) Solubilities were measured as $0.0016-0.0041 \mathrm{~mol} \%$ for $\mathrm{Mg}$ and $0.0006-0.0021 \mathrm{~mol} \%$ for $\mathrm{Ca}$ at $1373-1623 \mathrm{~K}$.

(2) The excess Gibbs energies of $\mathrm{Mg}$ and $\mathrm{Ca}$ in solid $\mathrm{Si}$ werd determined from the measured solid solubilities as follows:

$$
\begin{aligned}
& R T \ln \gamma_{\mathrm{Mg}(s) \text { in solid Si }}^{\circ} \\
& \quad=193,000( \pm 52,000)-69.8( \pm 34) T(\mathrm{~J} / \mathrm{mol}) \\
& R T \ln \gamma_{\mathrm{Ca}(s) \text { in solid Si }}^{\circ} \\
& \quad=140,000( \pm 35,000)-72.6( \pm 23) T(\mathrm{~J} / \mathrm{mol})
\end{aligned}
$$

(3) The temperature dependence of the solid solubilities was estimated, and the maximum solubility was $0.0040 \mathrm{~mol} \%$ at $1560 \mathrm{~K}$ for $\mathrm{Mg}$ and $0.0014 \mathrm{~mol} \%$ at $1580 \mathrm{~K}$ for $\mathrm{Ca}$.

\section{Acknowledgement}

The authors are grateful to Prof. Hiroyuki Shibata and Mr. Masanori Tashiro for their help with conducting solubility measurement by electron probe micro-analyzer analysis.

\section{REFERENCES}

1) K. Suzuki, T. Sugiyama, K. Takano and N. Sano: J. Jpn. Inst. Metals 54 (1990) 168-172.

2) H. Fujiwara, J.Y. Liang, K. Takeuchi and E. Ichise: Mater. Trans., JIM 37 (1996) 923-926.

3) H. Fujiwara, J.Y. Liang, K. Miyata, E. Ichise and R. Otsuka: J. Jpn. Inst. Metals 60 (1996) 65-71.

4) L.A.V. Teixeira and K. Morita: ISIJ Int. 49 (2009) 783-787.

5) K. Morita, K. Kume and N. Sano: ISIJ Int. 40 (2000) 554-560.

6) K. Kume, K. Morita, T. Miki and N. Sano: ISIJ Int. 40 (2000) 561-566.

7) K. Morita and T. Miki: Intermetallics 11 (2003) 1111-1117.

8) H. Sigmund: J. Electrochem. Soc. 129 (1982) 2809-2812.

9) W.G. Pfann: JOM 203 (1955) 961-964.

10) B. Sopori, W. Chen, J. Madjdpur and N.M. Ravindra: J. Electron. Mater. 28 (1999) 1385-1389.

11) H. Kobatake, H. Fukuyama, T. Tsukada and S. Awaji: Meas. Sci. Technol. 21 (2010) 025901.

12) A.T. Dinsdale: Calphad 15 (1991) 317-425

13) H. Feufel, T. Gödecke, H.L. Lukas and F. Sommer: J. Alloy. Compd. 247 (1997) 31-42.

14) J.C. Anglezio, C. Servant and I. Ansara: Calphad 18 (1994) 273-309.

15) F.A. Trumbore: Bell Syst. Tech. J. 39 (1960) 205-233. 